\title{
Sustainable space mining
}

\author{
Renewed investment in lunar exploration (and beyond) will benefit basic research and applied science, but we need \\ to tread carefully in order to prevent the exploitation of extraterrestrial resources.
}

( ur species tends to dream big, especially when it comes to space exploration. Blue Origin recently unveiled its plans for the Blue Moon lander, which aims to "enable a sustained human presence on the Moon". Besides being a destination, the Moon is also a source of water, which could be electrolysed to produce oxygen and hydrogen for fuel, and possibly helium-3, a fuel source for clean nuclear energy; hence the Moon is a natural stepping stone for space exploration. NASA is already planning a lunar Gateway - a spacecraft with living quarters, research laboratories and docking points for spaceships - that will orbit the Moon and provide access to the lunar surface.

A few days after the Blue Moon announcement, on 16 May, NASA announced its collaboration with 11 US companies to develop prototypes for the Human Landing System as part of the Artemis Moon missions to return humans to the Moon by 2024. These aerospace companies include the seasoned Lockheed Martin and Northrop Grumman as well as the newer Blue Origin and SpaceX. Crucially, no single company is expected to deliver all aspects of transfer (from the lunar Gateway to low lunar orbit), descent (from low lunar orbit to the Moon) and ascent (from the Moon back to the Gateway). Through this public-private partnership, towards which private companies must contribute a minimum of $20 \%$ of the cost, investors will reduce NASA's share of the bill.

There's the rub: investors want to make a profit. Lines between research, space travel and resource harvesting will blur. In fact, let's be honest, many are only in it for the mining opportunities. Several companies (such as Asteroid Mining Corporation or Planetary Resources) are planning to search for water, rare-earth minerals, platinum, gold and iron, for example. A recent article by Martin Elvis and Tony Milligan attempts to mitigate the exploitation of the Solar System by proposing a 'one-eighth principle'. The authors suggest that to prevent a runaway exponential growth, we need to set ourselves a 'tripwire' before the final three doubling times in the disappearance of pristine wilderness. In other words, at a growth rate of $3.5 \%$, it will take 400 years to use up one-eighth of the total resources. This amount will double every 20 years thereafter, meaning that after the first alarm when we've used up one-eighth, there will be 60 years to prevent total devastation.

The question of whether asteroid mining is even legal is an open one - a veritable mine field. Only two international treaties deal with space mining. The 1967 Outer Space Treaty (Treaty on Principles Governing the Activities of States in the Exploration and Use of Outer Space, including the Moon and Other Celestial Bodies), signed by 108 countries but only ratified by 85 , is vague on the topic of exploration: "the exploration of outer space shall be done to benefit all countries and that space shall be free for exploration and use by all the States". At the time, a declaration on weapons was more urgent, and indeed the treaty is leak-tight in that respect; however, although weapons of mass destruction are banned in outer space, conventional weapons are not.

After the Moon landings (read about the history and outlook in Moon Rush: The New Space Race), it became more pressing to protect the Solar System from human exploitation. The Moon Treaty of 1979 leaves no ambiguity, stating that the Moon and other Solar System bodies "should be used exclusively for peaceful purposes, [and] ... their environments should not be disrupted". Moreover, "the Moon and its natural resources are the common heritage of mankind and ... an international regime should be established to govern the exploitation of such resources when such exploitation is about to become feasible". That time is now. The only problem is that none of the space-faring nations have ratified the agreement. That's correct: there is no legally binding international treaty to stop sovereign nations from plundering another celestial body.

Even worse, in 2015 the United States government unilaterally passed the US
Commercial Space Launch Competitiveness Act. It magnanimously states that US citizens "shall be entitled to any asteroid resource or space resource obtained, including to possess, own, transport, use and sell the asteroid resource or space resource obtained in accordance with applicable law, including the international obligations of the United States." Luxembourg was quick to follow suit, further relaxing the US requirement that a company's stakeholders must live in the country. Several countries have signed up to Luxembourg's legislation.

Is this the new Wild West though? We do not want to repeat the mistakes of the Earth's colonial past, after all. Therefore, now is the time to put in place safeguards to protect the rest of the Solar System from the kind of gross mismanagement witnessed on Earth. Besides the Moon, other planets, minor planets and near-Earth asteroids will be visited in the name of research and exploration.

These missions will be a huge boon for science and technology, as several articles in this month's issue show. From a basic science point of view, in a Comment Ralph Lorenz warns of the need for rigorous statistical tools when searching for life on distant ocean worlds. In their Perspective, Tao Zhang and collaborators discuss robotic exploration of regolith samples and present an updated overview of China's deep space exploration plans up to at least 2028. They are ambitious, and the current Change 4 mission will inform a future crewed lunar landing as well as a sample-return mission to Mars. And finally, in a Comment Charles Cockell considers the meaning of no evidence for life on Mars, and what we can learn from it. Would that really mean that life never existed there?

The need to explore is inherently human, and every successful space mission brings delight to the international community. But let us learn from past mistakes and manage space resources sustainably.

Published online: 7 June 2019 https://oi.org/10.1038/s41550-019-0827-7 